\title{
Landscape genetics of an endangered lemur (Propithecus tattersalli) within its entire fragmented range
}

\author{
ERWAN QUÉMÉRÉ,*+ BRIGITTE CROUAU-ROY,*+CLÉMENT RABARIVOLA,§ EDWARD E. \\ LOUIS JR $\uparrow$ and LOUNÈS CHIKHI†‡ \\ †CNRS UMR EDB, Toulouse, France, *Université Paul Sabatier UMR 5174 EDB, 118 route de Narbone Toulouse, France, \\ †Instituto Gulbenkian de Ciência, Rua da Quinta Grande, no. 6, 2780-156 Oeiras, Portugal, §Université de Mahanjanga, \\ Faculté des Sciences, Campus Universitaire Ambondrona BP 652401 Mahajanga, Madagascar, - Center for Conservation and \\ Research, Henry Doorly Zoo, 3701 South 10th Street, Omaha, NE 68107, USA
}

\begin{abstract}
Habitat fragmentation may strongly reduce individuals' dispersal among resource patches and hence influence population distribution and persistence. We studied the impact of landscape heterogeneity on the dispersal of the golden-crowned sifaka (Propithecus tattersalli), an endangered social lemur species living in a restricted and highly fragmented landscape. We combined spatial analysis and population genetics methods to describe population units and identify the environmental factors which best predict the rates and patterns of genetic differentiation within and between populations. We used non-invasive methods to genotype 230 individuals at 13 microsatellites in all the main forest fragments of its entire distribution area. Our analyses suggest that the Manankolana River and geographical distance are the primary structuring factors, while a national road crossing the region does not seem to impede gene flow. Altogether, our results are in agreement with a limited influence of forest habitat connectivity on gene flow patterns (except for North of the species' range), suggesting that dispersal is still possible today among most forest patches for this species. Within forest patches, we find that dispersal is mainly among neighbouring social groups, hence confirming previous behavioural observations.
\end{abstract}

Keywords: causal modelling, dispersal, habitat fragmentation, lemur, primate, Propithecus tattersalli, spatial autocorrelation

Received 10 April 2009; revision received 19 January 2010; accepted 28 January 2010

\section{Introduction}

Habitat loss and fragmentation are among the greatest threats to biodiversity worldwide (Myers et al. 2000; Ganzhorn et al. 2003), particularly so for tropical ecosystems (Sala et al. 2000; Foley et al. 2005; Laurance \& Peres 2006). They reduce habitat area, quality and connectivity for many wild species with potentially dramatic consequences for population viability (Andrén 1994; Fahrig 2003; Walker et al. 2008). In particular, it can lead to a rapid decline of population size and genetic variation within habitat fragments (Crnokrak \& Roff 1999; Frank-

Correspondence: E. Quéméré, Fax: (+33) 561557 327;

E-mail: erwan@quemere.fr and L. Chikhi, Fax: (+33) 561557 327, E-mail: chikhi@cict.fr ham et al. 2002; Frankham 2005; Olivieri et al. 2008; Craul et al. 2009). It is believed that, in the medium or long term, it can lead to an increase in the level of inbreeding, the erosion of species' evolutionary potential, and an increase in the risk of extinction (Saccheri et al. 1998; Keller \& Waller 2002; Johansson et al. 2007). Local extinctions of small fragmented populations are relatively common (Fahrig \& Merriam 1994; Kindlmann \& Burel 2008). Consequently, persistence of species strongly depends on the ability of dispersing individuals to move across heterogeneous landscapes to re-colonize empty patches and maintain the functional connections among remaining populations. One aim of conservation is to identify the most suitable areas in the matrix (i.e. putative corridors) to restore and maintain habitat connectivity among populations (Taylor \& Fahrig 2006; Cushman 
et al. 2009). Consideration of the matrix heterogeneity and the level of permeability of its components to dispersal movements are thus key issues for the management of endangered species with patchy distributions (Taylor et al. 2006; Lindenmayer et al. 2008).

The effects of environmental features on individual dispersal are difficult to assess using mark-recapture or radio-tracking approaches because a relatively large number of individuals have to be captured and monitored (Vignieri 2005; Cushman 2006; Broquet et al. 2006). Furthermore, these direct methods are time consuming, often invasive and thus not generally suitable for the study of threatened species. Genetic data, which can be obtained using non-invasive sampling methods, offer an attractive alternative approach to infer patterns of dispersal. Genetic methods can highlight the natural and anthropogenic factors shaping migration patterns between habitat patches (Holderegger \& Wagner 2008; Balkenhol et al. 2009). The genetic study of functional habitat connectivity (i.e. the 'degree to which the landscape impedes or facilitates movements among resources patches', Taylor et al. 2006) has received growing interest principally because of the improvement of methodological and technical tools for assessing habitat heterogeneity (e.g. high-resolution satellite images, Geographic Information Systems). This has favoured the emergence of 'Landscape genetics' (Manel et al. 2003), a new interdisciplinary research area combining population genetics and landscape ecology for quantifying the effect of landscape composition, configuration and matrix quality on spatial patterns in neutral and adaptive genetic variation (Storfer et al. 2007; Holdegger \& Wagner 2008). For instance, several recent landscape genetic studies used previously existing data with new statistical tools to uncover the spatial genetic discontinuities corresponding to anthropogenic barriers such as roads or canals (Epps et al. 2005; Coulon et al. 2006; Perez-Barberia et al. 2008; Radespiel, et al. 2008b). Others characterized environmental features that facilitate migration such as riparian areas in jumping mice (Vignieri 2005), high-slope areas in bighorn sheep (Epps et al. 2007) or eucalyptus forests in small marsupials (Banks et al. 2005).

In this study, we investigated the impact of forest fragmentation on patterns of genetic differentiation in the golden-crowned sifaka (Propithecus tattersalli). This relatively large, social species of lemur is found only in the Daraina region of north-eastern Madagascar (Fig. 1) and has one of the most limited ranges of any lemur $\left(2450 \mathrm{~km}^{2}\right)$ (Mittermeier et al. 2006). The island of Madagascar is among the most important biodiversity hotspot and conservation priority areas in the world (Myers et al. 2000; Ganzhorn et al. 2003). However, deforestation and habitat fragmentation have increased precipitously during the 20th century, primarily due to human pressure and particularly in the evergreen forests along the eastern coast and the deciduous forests of western Madagascar (Green \& Sussman 1990; Smith 1997; Harper et al. 2007). Most previous studies have focused on the impact of habitat fragmentation on species richness (Ganzhorn et al. 2003; Scott et al. 2006; Dunham et al. 2008; Allnutt et al. 2008) or on the distribution of species among and within patches (Lehman et al. 2006; Irwin 2007; Quéméré et al. 2010). However, for Malagasy species, the genetic consequences of habitat fragmentation have been poorly studied (but see Olivieri et al. 2008; Radespiel et al. 2008a,b Craul et al. 2009 for recent exceptions). The Daraina region, where $P$. tattersalli lives, is expected to suffer from significant disturbances in the near future and was identified as a high-priority area for biodiversity conservation (Ganzhorn et al. 1999; ZICOMA, 1999). While we have shown that the population densities were higher than previously thought (Quéméré et al. 2010), recent political instability has led to a renewed level of hunting and poaching. Thus, to facilitate conservation in this species, studies focused on identifying the natural and anthropogenic factors influencing patterns of dispersal and levels of genetic diversity are needed.

To characterize the $P$. tattersalli spatial genetic structure, we first combined field observations and remote sensing data within a Geographic Information System (GIS) to provide an a priori definition of the landscape heterogeneity in Daraina area. Specifically, we assessed (i) the extent of forest habitat and structural connectivity and (ii) environmental features such as rivers, roads or riparian corridors that may impede or facilitate individual dispersal. To obtain the genetic data we used a non-invasive sampling strategy (Taberlet et al. 1997; Kohn et al. 1999) to genotype 230 individuals from the main forest patches of the golden-crowed sifaka range using 13 microsatellites. We first assessed the level of genetic diversity across all individuals sampled and then within each of the main inhabited forest patches. To build a species-specific model of habitat suitability (i.e. a posteriori definition of the landscape reflecting the golden-crowned sifaka behavioural response in terms of distribution and dispersal), we employed two individual-based approaches: (i) the commonly used Bayesian clustering method STRUCTURE (Pritchard et al. 2000; Falush et al. 2003), which identifies panmictic subpopulation units (i.e. clusters) delineated by discrete boundaries and (ii) a causal modelling approach based on resemblance matrices (Legendre 1993; Cushman et al. 2006) which evaluates the ability of alternative hypotheses to identify a landscape model (i.e. a combination of environmental factors) that predicts rates and patterns of gene flow. We compare the results from the two approaches and discuss their relevance for $P$. tattersalli conservation strategies. 


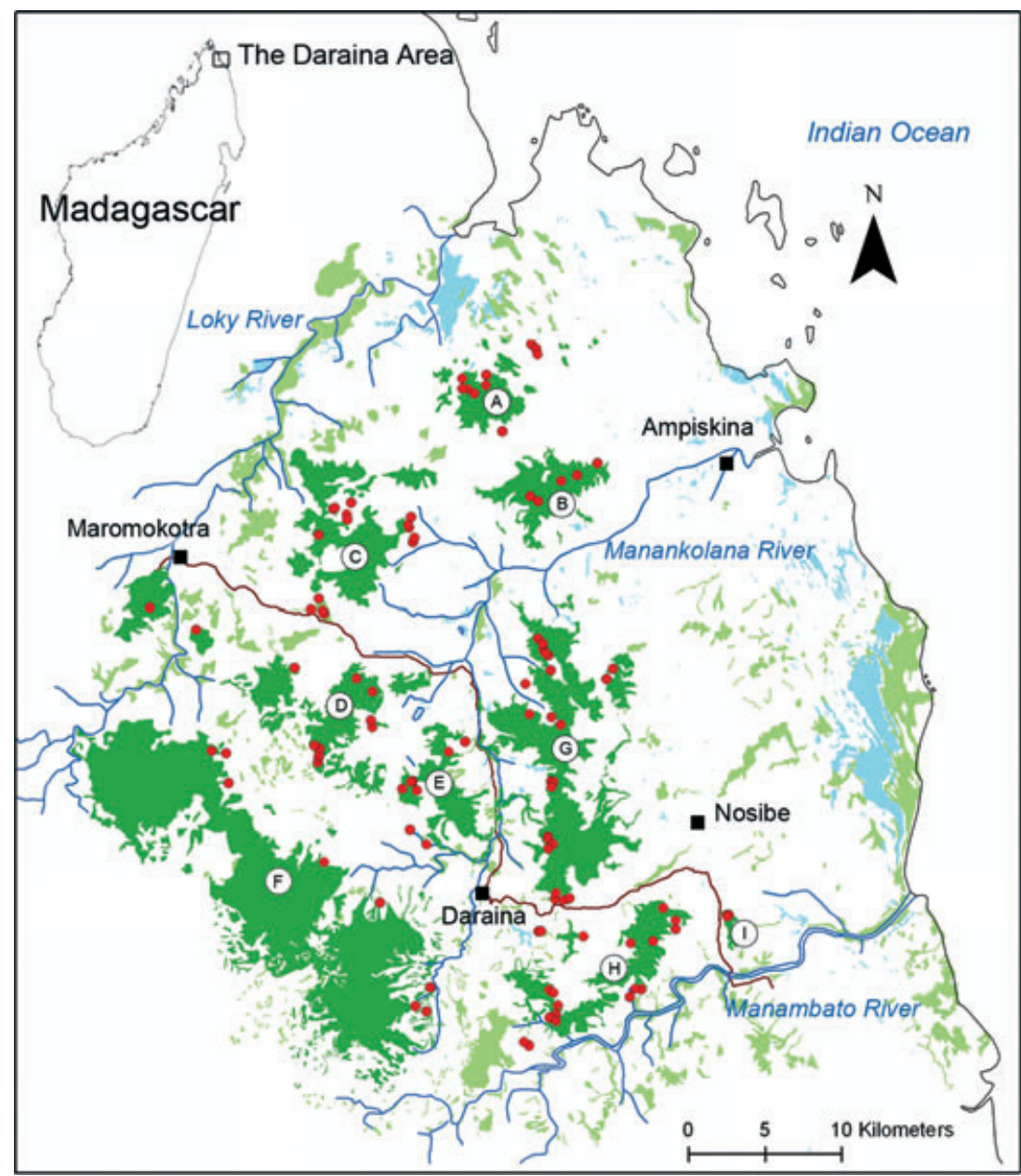

Fig. 1 Sampling distribution of goldencrowned sifakas. Distribution range of Propithecus tattersalli in the Daraina area. The green colour represents the forest fragments where we detected $P$. tattersalli individuals. Red circles correspond to the location of the sampled social groups. The commune chieftowns are represented by black squares. The national road is represented by a brown line and the main rivers by blue lines. The correspondence between circled letters and forest fragment complex name is indicated in Table 1.

\section{Methods}

\section{Study area and landscape structure characterization}

To capture the landscape heterogeneity in the Daraina region and differentiate forest and non-forest vegetation areas, we conducted a landscape classification using a LandSat Thematic Mapper imagery acquired in 2002 and the maximum likelihood supervised method, implemented in the software ENVI 4.1. The accuracy of the classification was checked in the field and using SPOT imagery. The forest habitat in the Daraina region is highly fragmented, covering about $17 \%$ of the total area (44,000 ha) and with only $6 \%$ of the patches larger than 1000 ha $(n=9)$ and $20 \%$ larger than 100 ha $(n=28)$ (Fig. 1). Forest patches (mainly lowland dry forests) are surrounded by a heterogeneous matrix of riparian gallery forests, agricultural areas, zebu cattle grazing pastures, human settlements and by large grasslands and dry scrubs. Some of the forest patches were included in 2005 in the Station Forestière à Usages Multiples-'Multiple Usage Forest Station' (SFUM) Loky-Manambato managed by the Malagasy NGO
Fanamby, in order to minimize direct anthropogenic pressures such as intensive wood and mining exploitation. In practice, it appears that golden-crowned sifaka populations are present both within and outside the SFUM (Vargas et al. 2002; Quéméré et al. 2010). Finally, it is important to note that the Daraina region, delineated by the Loky and the Manambato rivers, is crossed by a third large river (the Manankolana River) flowing south to northeast and by the unpaved national road RN5A running southeast to northwest (Fig. 1).

\section{Sampling strategy and DNA analysis}

We conducted a non-invasive hierarchical sampling design including social groups from across the species range. Faecal samples were collected in all the main forest patches within the golden-crowned sifaka's distribution (Fig. 1). Within the larger patches, we also collected samples from several valleys, and within these valleys several neighbouring social groups were sampled to capture genetic variation at multiple spatial scales. We collected faecal pellets for genetic analyses during two field missions in 2006 and 2008. The data 
from 292 putative individuals belonging to 107 social groups are analysed here. All the samples were obtained immediately after defecation as described in Quéméré et al. (2009), and their geographical coordinates were assigned at the faeces collection point. DNA extraction was performed following the 2CTAB/PCI protocol adapted from Vallet et al. (2008). The extracted DNA was amplified using a set of 13 microsatellite loci isolated for Propithecus tattersalli (8 loci) and for the closely related species $P$. coquereli (5 loci) (see Quéméré et al. 2009 for details of protocols). In order to ensure the reliability of genotypes, we performed a sequential replicate-based approach as described in Frantz et al. (2003). This was found to be more efficient for P. tattersalli than the commonly used multi-tube approach (Taberlet et al. 1996) because the same reliable consensus genotypes were reached using a smaller mean number of replicates (Quéméré et al. 2009). To quantify the reliability of our genotyping, we calculated the mean quality index (QI) across samples and loci following the rules defined in Miquel et al. (2006). Using the software CERVUS 3.03 (Kalinowski et al. 2007), we computed the probability of identity (pID) (i.e. the overall probability that two individuals drawn at random from a given population share identical genotypes at all typed loci) and identity assuming sibling (pIDsib).

\section{Genetic diversity and structure analysis}

The level of genetic variation for the whole data set and within each of the nine studied forest patches was measured as the mean number of alleles per locus (MNA), the allelic richness (AR), the observed heterozygosity $\left(H_{\mathrm{o}}\right)$ and the expected heterozygosity $\left(H_{\mathrm{e}}\right)$ (Nei 1978). In order to investigate the level of genetic structure among forest patches, we estimated the pairwise $F_{\text {st }}$ between all populations (Wright 1978) following Weir \& Cockerham (1984). Departure from HWE was calculated with $F_{\text {is }}$ (Wright 1978). We tested the significance of $F_{\text {is }}$ and $F_{\text {st }}$ values using permutations. We performed all analyses using the GENETIX software (Belkhir et al. 1996-2004), except for Allelic Richness (AR), which was computed using FSTAT (Goudet 2001).

\section{Identification of population units and structuring environmental factors}

STRUCTURE analysis. To detect discontinuities in genetic variation and define genetically distinct units, we first used the commonly used individual-based clustering Bayesian methods implemented in the STRUCTURE 2.2 (Pritchard et al. 2000; Falush et al. 2003). We performed 10 runs of 500,000 iterations with a burn-in period of 100,000 for each $K$ value (with $K$ ranging from 1 to 12 for the first level analysis) using the admixture model and assuming correlated allele frequencies (Pritchard et al. 2000; Falush et al. 2003). We used a uniform prior for alpha, the parameter representing the degree of admixture, with a maximum of 10.0 and set Alphapropsd (the standard deviation of the proposal distribution) to 0.05 . Lambda, the parameter representing the amount of correlation in the parental allele frequencies, was set at 1.0 and the prior $F_{\text {st }}$ was set to the default values with a mean of 0.01 and a standard deviation of 0.05 . For each run, we checked the stabilization of the likelihood. To determine the optimal number of clusters, we compared the log-likelihood of the data given the number of clusters $(\operatorname{Ln} P(X \mid K))$, evaluated the individual membership coefficient (Q) (Pritchard et al. 2007) and computed the standardized second order rate $\Delta K$ of change of $L n$ $P(X \mid K)$ (Evanno et al. 2005), for different values of $K$. The $\Delta K$ method is known to detect only the uppermost level of structure (Evanno et al. 2005). We thus repeated the process in a hierarchical way until no substructure could be uncovered and by assigning at each hierarchical level, the individuals to the group where more than $90 \%$ of their genome is assigned (i.e. membership proportion $Q>0.9$ ). Since the golden-crowed sifaka individuals within social groups are expected to be closely related (Meyers 1993), the 'optimal' value of $K$ might be reflecting family-induced structure rather than the overall geographical population structure as it has been recently noticed in gorillas (Bergl \& Vigilant 2007) or in salmon and simulated data (Anderson \& Dunham 2008). We, therefore, treated the clustering analyses as a data-exploration tool as was suggested by Chikhi and Bruford (2005) or Anderson and Dunham (2008). Since the assumption of correlated allele frequencies may also lead to an overestimation of $K$ (Pritchard et al. 2007), we repeated the analyses using the independent allele frequency model with lambda set to 1.0. We report only the results from runs assuming correlated allele frequencies, since the outcomes of our analyses were not affected by this change in model choice. To discuss the relationship between genetic discontinuities and environmental features, we computed the mean membership coefficients of each social group for each cluster and plotted the results on the map of the Daraina region. These coefficients were assigned to the group sampling locations, and we used the inverse distance weighted (IDW) interpolation function implemented in ArcGis 9.2 to predict the overall pattern of cluster membership through the species range.

CAUSAL MODELLING analysis. To identify the environmental factors influencing $P$. tattersalli dispersal across landscape, we employed a causal modelling on resemblance approach (Legendre 1993; Cushman et al. 2006). 
This factorial, multi-model approach aims to combine least cost path modelling and partial Mantel tests to identify the landscape organizational models (i.e. combination of environmental factors) which appear to drive the patterns of genetic relatedness among individuals (Cushman et al. 2006). Contrary to clustering methods, this approach needs to define a priori the environmental factors potentially driving genetic structure. We detail now the different steps of this approach.

First step-identification of potential drivers of genetic structure. By combining field observations, remote sensing data and GIS tools, we identified four potential drivers of $P$. tattersalli genetic structure in Daraina area. These are the geographical distance [Factor D], the national road (as a barrier) [Factor R], the Manankolana River (as a barrier) [Factor M], and the forest habitat structural connectivity (for simplicity we refer to it as 'canopy') [Factor C]. We did not test the effect of slope/altitude since $P$. tattersalli range mostly corresponds to lowland landscapes. Human density was also not considered since it is relatively low in the Daraina area and a strong fady (i.e. local taboo) limited the direct pressures on the golden-crowned sifaka (poaching and hunting mentioned above appear to have been caused by non-local people settling in the region during a 'gold rush' in the 1990s and during the recent political instability).

Second step - computation of genetic and resistance distance matrices. Genetic dissimilarity [G] among individuals was estimated by computing the matrix of Rousset (2000)'s genetic distance $a_{\mathrm{r}}$ between pairs of individuals using the program SPAGeDI (Hardy \& Vekemans 2002). The isolation-by-distance hypothesis [D] was modelled as a single hypothesis with genetic dissimilarity predicted to increase linearly with Euclidian distances. A matrix of Euclidian distances was thus computed between pairs of individual locations. The two Isolation-by-barrier hypotheses (Isolation-by-road [R] or Manankolana River [M]) were represented as categorical model matrices (Legendre \& Legendre, 1998) with 0 s and $1 \mathrm{~s}$ for pairs of individuals on the same or different side of the barrier, respectively. To model the Isolation-by-canopy hypothesis [C], we computed three resistance surfaces representing three level of selectivity for the forest connectivity. We first carried out a gradual forest numeric model (FNM) (Coulon et al. 2004) from the landscape classification (see above): the smoothing function implemented in the software ENVI 4.1 was used to assign a value between 1 and 10 to each pixel corresponding to $30 \times 30 \mathrm{~m}^{2}$ squares indicating the amount of open area surrounding the pixel within a radius of $200 \mathrm{~m}$. (i.e. resolution of the friction maps). We used this value because (i) it corresponds to the estimated radius of sifaka social groups' territory (Meyers 1993) and (ii) it allows us to consider small elements like riparian forests that are likely to favour sifakas dispersal (Adriaensen et al. 2003; Broquet et al. 2006). The three isolation-by-canopy resistance surfaces [C1, C2 and C3] corresponded to a low/medium/high level of selectivity in which the most opened areas are two/five/ten times, respectively, more difficult to cross than the most forested areas (Fig. S1, Supporting Information). We then used these resistance surfaces to estimate cost distances between individuals and to produce three pairwise matrices using the PATHMATRIX tool (Ray 2005). Cost distances are the cumulative costs corresponding to the least-cost route between pairs of individual locations.

Third step-identification and test of organizational models. We considered 15 possible organizational models corresponding to all the patterns of causality among the four factors described above (Table 2c and Fig. S2, Supporting Information). To assess the support of each of these models, we followed the procedure detailed in Cushman et al. (2006). Each of the 15 models is related to a set of hypotheses corresponding to statistical relationships between genetic structure and putative structuring environmental factors (Table $2 \mathrm{a}$ and $\mathrm{c}$ ). Support for a model can be simply computed as the number or the proportion of statistical predictions that are fulfilled. A model is fully supported only if the entire set of hypotheses is verified. To evaluate the relationship between the genetic structure and each of the potential factors, we used simple (Mantel 1967) and partial (Smouse et al. 1986) Mantel tests within a causal modelling framework (Legendre 1993). We first computed the Mantel correlation and associated Monte Carlo $P$ value for each simple and partial Mantel correlation between genetic-distance matrix and the matrices corresponding to the different factors or set of factors (Table $2 b$ ). We then compared the significant and non-significant (NS) tests to the expectations under the 15 models (Table 2c) to identify the organizational model with the greatest support (i.e. most consistent with the observed pattern of genetic data). For each model, we computed a support rate corresponding to the ratio of the number of non-rejected hypotheses to the total number of tested hypotheses. The confidence intervals of the support rates were obtained using a resampling procedure (Manly 1997) in which we randomly selected $75 \%$ of the 230 individuals without replacement (100 iterations). We recomputed the support rates for each of the 15 models using the 100 data sets repeating the procedure detailed above. 


\section{Spatial genotypic structure at the patch scale}

Isolation-by-Euclidian distance appears to be an important factor structuring genetic diversity in $P$. tattersalli populations (see the 'Results' section below). In order to investigate the spatial scale of variation of the dispersal process, we performed a spatial autocorrelation analysis in GENALEX 6.2 (Peakall \& Smouse 2006) for individuals belonging to the same forest patch hence assuming the Euclidian distance and the rate of dispersal as the only factors influencing genetic structure. Data from all patches were combined using the 'Multiple Pops' option. The spatial autocorrelation analysis assesses the genetic similarity between pairs of individuals at different geographical distance classes. These classes were defined so as to (i) represent sensible biological classes (see below), (ii) be of similar length (in meters), and (iii) have a minimum number of within class comparisons. The first distance class was defined to only include comparisons among individuals from the same social group (i.e. the 'within groups' class). The following distance classes corresponded to increments of $500 \mathrm{~m}$, up to $5000 \mathrm{~m}$, and had between 58 and 264 pairwise comparisons. The autocorrelation patterns may result from processes other than dispersal, such as mutation, which is known to be affected by sampling scheme (Guillot et al. 2009). Since we collected the samples at random across the forest patches (Fig. 1), we assume that our sampling scheme does not reflect species density and is not informative about the process. Thus, the patterns of autocorrelation should reflect the sifaka dispersal and their social and reproductive structure. Since behavioural data indicated that $P$. tattersalli dispersal is biased toward neighbouring social groups (Meyers 1993), we should obtain a significant positive autocorrelation in the first distance classes and the correlogram should flatten out at the scale where dispersal is not connecting social groups (Aars et al. 2006). The significance of $r$ values was tested by doing 1000 random permutations of the data to compute the 95\% confidence interval about the null hypothesis of no spatial substructure $(r=0)$ compared with the bootstrap 95\% confidence intervals around each estimate of $r$ (Peakall et al. 2003).

\section{Results}

\section{Genetic diversity and patterns of differentiation among patches}

We obtained multi-locus genotypes from 250 out of the 292 extracted samples $(\sim 78 \%)$. Overall the faecal samples were of good quality, with a mean QI per sample of $0.81(\mathrm{SD}=0.16)$ and the mean QI per locus of 0.82 $(\mathrm{SD}=0.04)$. This relatively high quality is not necessar- ily surprising given that all samples were immediately collected after defecation. All 13 loci used were polymorphic with an average of 7.7 alleles $(S D=1.98)$ per locus across all samples. The pID (Evett \& Weir 1998) was $8.82 \times 10^{-14}$ and the pIDsib (Evett \& Weir 1998) was $7.98 \times 10^{-6}$ for a 13-locus genotype, allowing ample power to discern individuals. Among the 250 samples, 20 were discarded as they corresponded to the same multi-locus genotype as another individual from the same social group at all 13 loci. We note here that we expected this to happen since defecation of the members of a sifaka group often occurs over a relatively short period of time and often under the same tree. Based on our 2006 experience, our sampling strategy during the 2008 fieldwork season was hence done so as to ensure that all individuals were sampled in a group, accepting the risk of sampling the same individual more than once. The remaining 230 individuals were thus considered for the analyses. Altogether this corresponded to a total of 2960 genotypes (i.e. 30 missing genotypes $\sim 1 \%$ ).

Genetic diversity of golden-crowned sifakas across all nine forest patches, as measured by $H_{\mathrm{e}}$ had a mean value of 0.66 , ranging between 0.57 (Antsiasia) and 0.73 (Ampondrabe). The average AR was 3.83 ranging from 3.00 (Antsiasia) to 4.36 (Bekaraoka) (Table 1). Average $H_{\mathrm{o}}$ values were slightly higher than $H_{\mathrm{e}}$ in most of the sampling sites resulting in mostly negative $F_{\text {is }}$ values ranging from -0.18 to 0.01 with a significant departure from HWE for three sites (Bobankora, Ampondrabe and Antsaharaingy). In these three cases, significant heterozygosity excess was observed for only one to four loci which appear to drive the overall result. We found that the genetic diversity levels within all forest patches were also relatively high and that this AR was slightly correlated with patch surface areas but not significantly (Pearson correlation, $P$ value $=0.06$ ). Levels of differentiation, as measured by pairwise $F_{\mathrm{st}}$, were significant between most of the sites (values ranging between 0.03 and 0.30 -Table S1, Supporting Information) except between the neighbouring Bemokoty and Tsarahitsaka forest patches $\left(F_{\mathrm{st}}=0.01\right)$. The highest $F_{\text {st }}$ values were found for Antsiasia (average pairwise $F_{\text {st }}=0.2$ ) and Antsaharaingy (0.16) located in the far northern and south-eastern edges of the distribution area, respectively (Patches I and A-Fig. 1). By excluding these two isolated patches, which were responsible for the largest $F_{\text {st }}$ values, we observed that the level of differentiation among patches located on the same side of the Manankolana River was much more limited ( $F_{\text {st }}$ values between 0.01 and 0.07$)$ in comparison with the values obtained among patches located on different sides ( $F_{\text {st }}$ ranged between 0.09 and 0.16 ). 
Table 1 Summary statistics for the nine forest patches populations

\begin{tabular}{|c|c|c|c|c|c|c|}
\hline Forest massif [ID] & Sample size & MNA & $\mathrm{AR}$ & Ho & He n.b. & Fis \\
\hline ANTSAHARAINGY [A] & 22 & 4.62 & $3.29(0.75)$ & $0.69(0.19)$ & $0.58(0.15)$ & $-0.18^{* * *}$ \\
\hline AMPONDRABE [B] & 16 & 4.77 & $4.19(0.86)$ & $0.79(0.12)$ & $0.73(0.09)$ & $-0.08^{*}$ \\
\hline AMPOETANY [C] & 37 & 5.23 & $3.71(0.51)$ & $0.68(0.10)$ & $0.65(0.09)$ & -0.05 \\
\hline BEMOKOTY [D] & 25 & 5.08 & $3.99(0.77)$ & $0.69(0.13)$ & $0.67(0.10)$ & -0.03 \\
\hline TSARAHITSAKA [E] & 20 & 4.92 & $3.88(0.84)$ & $0.69(0.10)$ & $0.66(0.10)$ & -0.04 \\
\hline BAA $[F]$ & 18 & 5.15 & $4.05(0.87)$ & $0.69(0.15)$ & $0.69(0.09)$ & -0.01 \\
\hline BEKARAOKA [G] & 49 & 6 & $4.36(0.73)$ & $0.72(0.12)$ & $0.72(0.09)$ & 0.01 \\
\hline BOBANKORA [H] & 31 & 5.54 & $4.03(0.87)$ & $0.70(0.13)$ & $0.66(0.12)$ & $-0.07^{* *}$ \\
\hline ANTSIASIA [I] & 6 & 3 & $3.00(0.71)$ & $0.60(0.22)$ & $0.57(0.19)$ & -0.06 \\
\hline Average & 25 & 4.92 & $3.83(0.77)$ & $0.69(0.14)$ & $0.66(0.11)$ & -0.03 \\
\hline
\end{tabular}

$I D$, forest massif reference in Fig. 1 ; MNA, mean number of alleles; $H_{\mathrm{o}}$, observed heterozygosity; $H_{\mathrm{e}}$, n.b., unbiased expected heterozygosity; AR, allelic richness; Standard deviations are in brackets. ${ }^{*} P<0.05 ;{ }^{* *} P<0.01 ;{ }^{* * *} P<0.001$.

\section{Identification of population units and environmental factors}

STRUCTURE analysis. The STRUCTURE analysis showed that the likelihood of the data increased quickly up to $K=3$ and then reached an asymptote (data not shown). For $K>3$, the results were not consistent among runs and the uncovered genetics units corresponded to related individuals belonging to the same or neighbouring social groups. It thus appeared that $K=3$ captured the major genetic structure in our sample while producing a very high average value for $Q(0.92 \pm 0.11)$. The three clusters, $\mathrm{KA}, \mathrm{KB}$ and $\mathrm{KC}$, corresponded to three regions with limited overlap, and KA was mostly composed of individuals from east of the Manankolana River (Fig. 2). Using the method of Evanno et al. (2005), the results were at first slightly different as the highest $\Delta K$ value was obtained for $K=2$ which corresponded, with very few exceptions, to individuals sampled on the Eastern (i.e. KA) or Western (i.e. KB and $\mathrm{KC}$ ) sides of the Manankolana River (data not shown). When we repeated the $\Delta K$ analysis within these two main clusters, as suggested by Evanno et al. (2005), we found that the western river side group could be further divided into two subgroups with one genetically distinct group corresponding to most of the individuals from Antsaharaingy in the extreme north of the distribution area. We found no substructure on east of the Manankolana River (Fig. 2). When we interpolated the KA cluster membership coefficients obtained with STRUCTURE on the map of the Daraina region (Fig. 2), we observed that the main genetic discontinuity overlapped with the geographic location of the river, even though the analysis did not use any prior geographical information. In contrast, the genetic clusters did not coincide with the national road bisecting the area, although it is parallel to the river for about one third of its length. This strongly suggests that one of the main factors structuring present-day genetic diversity is the Manankolana River and not the road.

Causal modelling analysis. The results of the simple Mantel tests for the seven independent factors in Fig. 3 show (i) that all correlations are significant, but also that (ii) all correlation values are relatively similar (between 0.25 and 0.33), with only one exception, namely the road which exhibits a much lower value $(r=0.05)$. The two highest values appear to be those corresponding to the Manakolana River $[\mathrm{M}]$ and Euclidean distance [D] hypotheses, followed by the different 'canopy' models. For each of the 15 hypothetical organizational models, Table $2 \mathrm{c}$ represents the expected results of the causal modelling analysis in terms of partial Mantel tests. For instance, model 1 $[D+C+M]$ assumes that in Propithecus tattersalli gene flow is influenced by all factors except the road. If this model were correct, we would expect the first partial Mantel test corresponding to the correlation between road and pattern of gene flows controlling for distance (RG.D) to be NS because the road factor is absent of the model. We observed that this is indeed the case (Table $2 \mathrm{~b}, r=-0.06, P=1.00$ ). In order to make this Table 2 easier to read, we highlighted the cases where the $P$-value of the partial Mantel tests matched with the expectation of the model (i.e. when the hypothesis is thus consistent and hence potentially supported). The global support rates of the models (i.e. the ratio of the number of non-rejected hypotheses to the total number of tested hypotheses) vary between 0.14 $( \pm 0.06)$ for model 15 (only one prediction was correct) and $0.83( \pm 0.04)$ for model 1 (10 predictions out of 12 ) (Table 2c). None of the 15 models is fully supported, but seven models (models 1-7) seem to provide relative good predictions in terms of partial Mantel 


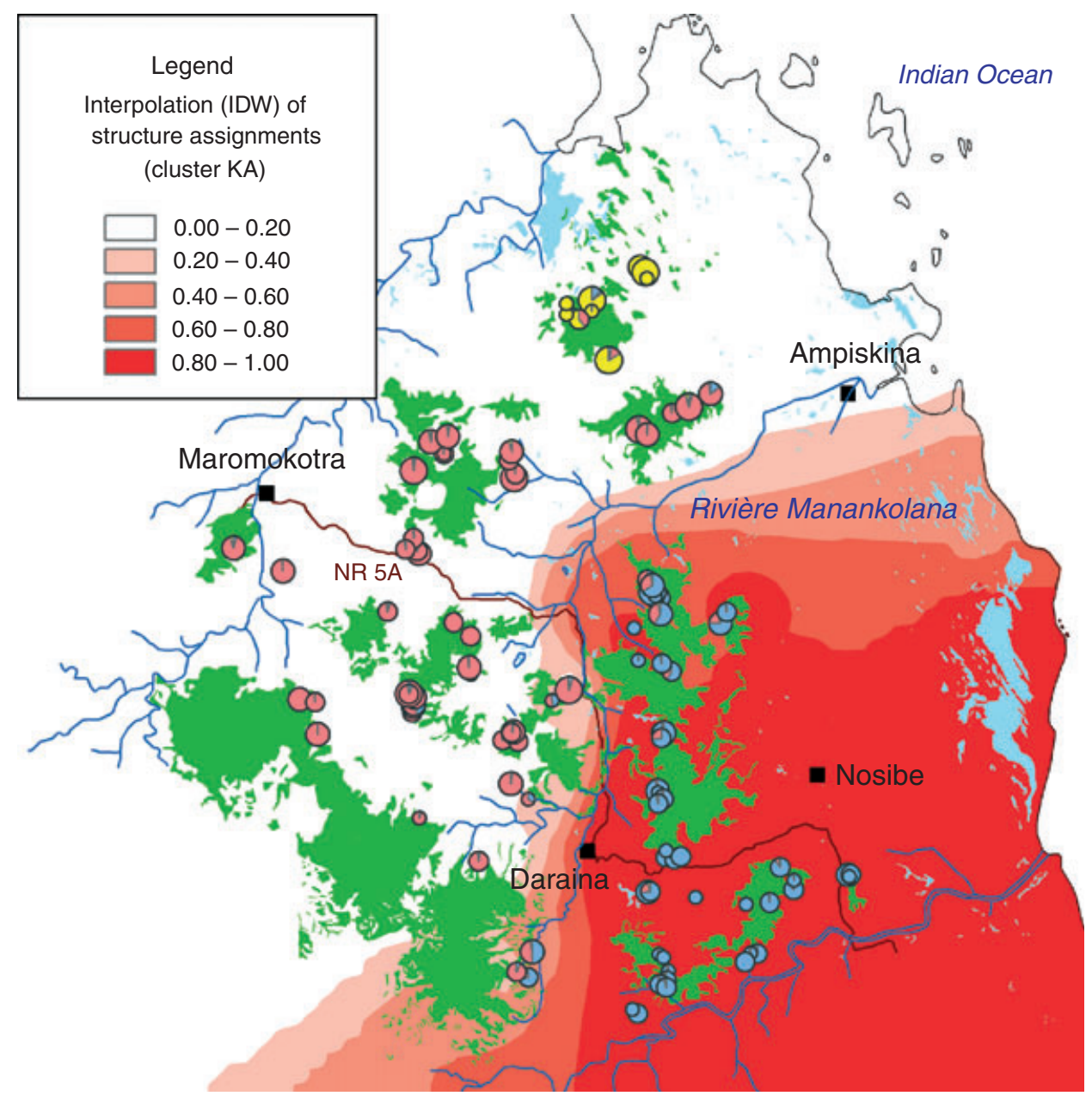

Fig. 2 Membership of social groups genetic clusters. The social groups are represented by pie charts at the location where they were sampled $(n=105)$. The size of the pie charts is proportional to the number of sampled individuals in the social groups (between one and five individuals). The colours indicate the average membership coefficients for each social group to each of the three clusters uncovered by STRUCTURE (blue, red and yellow colour for cluster KA, KB and KC, respectively). The red gradient illustrates the interpolated (IDW) membership coefficients of the cluster 1 (see text for details).

tests (support $>0.6$ ), three of which have support values $\geq 0.8$ (models 1-3). Among the six bestsupported models, five appear to have the geographical distance factor $[\mathrm{D}]$, three the Manankolana $[\mathrm{M}]$, or canopy $[\mathrm{C}]$ factor.

Identification of the best organizational model. To identify the best model, we considered not only the global support of each model but also analysed in detail the output of associated predictions. Indeed, the different factors are not independent and a partial Mantel test may reveal a significant correlation not because of the direct effect of a factor but rather through a correlation with another factor. For instance, we can see a significant canopy effect partialling out the river (Hypothesis CG.M, $P$ value $<0.01)$. However, we also observed that there is no effect of canopy controlling for distance (Hypothesis
CG.D, NS). This suggests that the effect of canopy in model 1 is caused by a correlation between canopy and geographic distance. In others words, model 1 should be

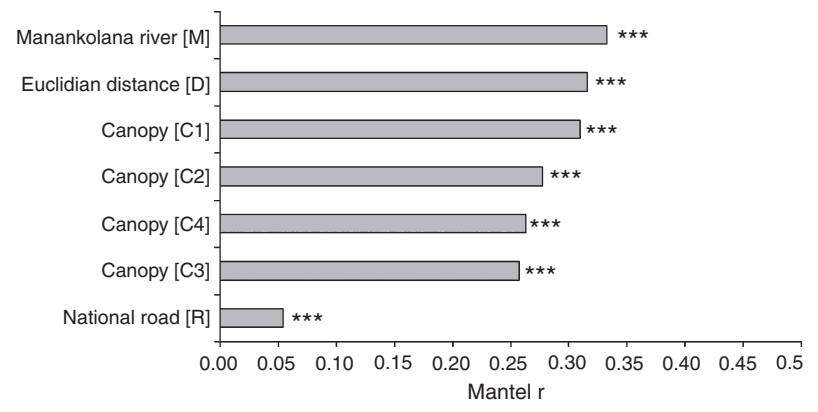

Fig. 3 Results of simple Mantel tests. ${ }^{*}=P<0.05$, ${ }^{* *} P<0.001$, ${ }_{* * * *} P<0.001$. 
Table 2 Evaluation of the 15 organizational models

(c)

(a) 15 Organizational models

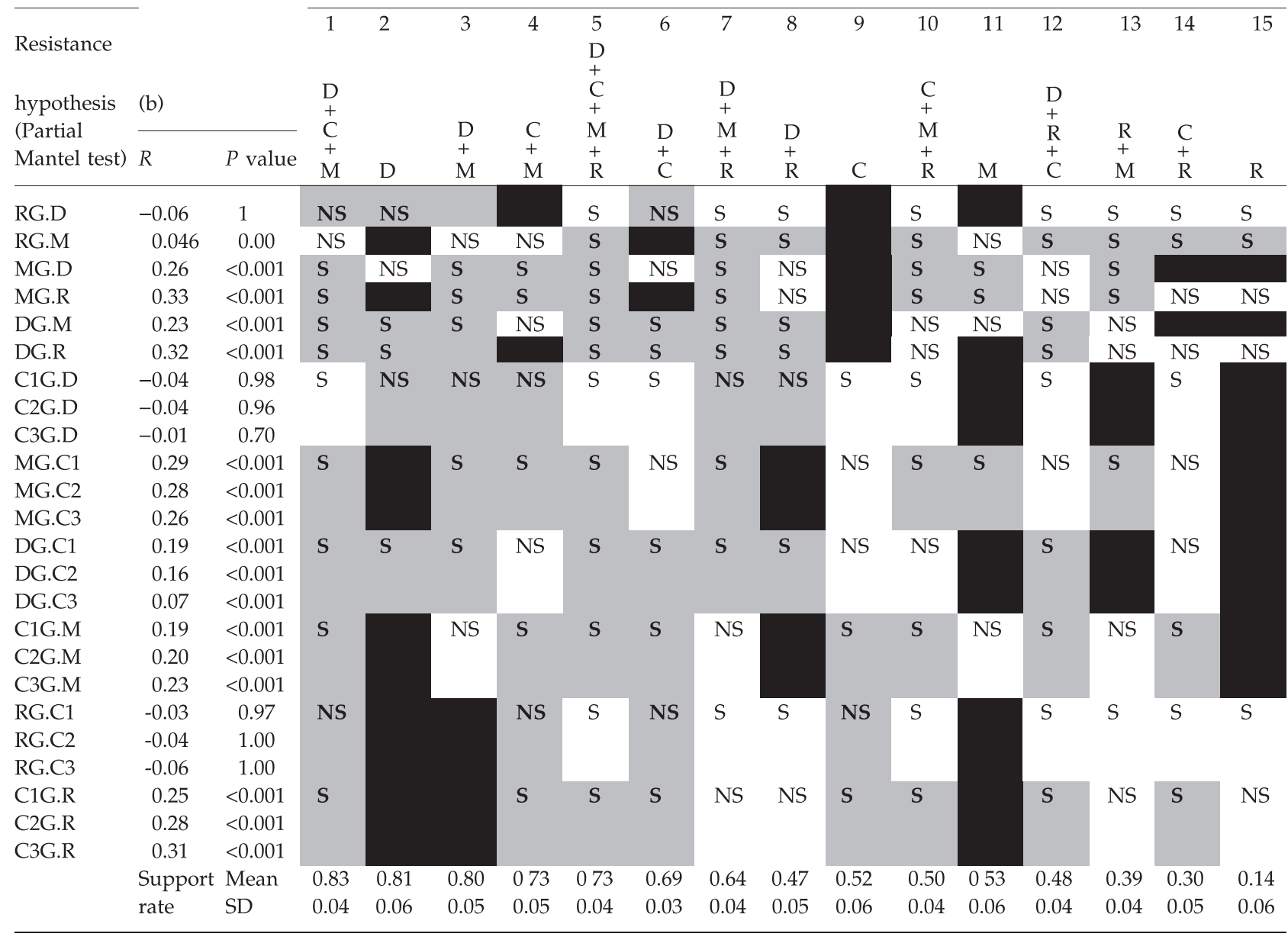

$\mathrm{F}=$ Forest $\mathrm{C}=$ Canopy $\mathrm{M}=$ Manankolana River $\mathrm{R}=$ Road $\mathrm{D}=$ Euclidian distance; $\mathrm{G}=$ Genetic distance.

In Table 2a, we represented the set of diagnostic resistance hypotheses (partial mantel tests) related to each model. A period separates the main matrices on the left from the covariate matrix on the right that are partialled out in the partial Mantel test. For example, RG.D is a partial Mantel test between the road (R) and the genetic distance (G) matrices with the geographical distance matrix (D) partialled out. For each model, the expectations for the Mantel tests were indicated in Table 2c. S and NS mean that the corresponding partial Mantel tests are expected to be significant or NS, respectively for this model. The grey boxes are a visual help to identify tests where the $P$ value (Table $2 b$ ) matched the expected result of the test (see text for a simple example). Boxes where a particular test is meaningless for a specific model were represented in black. The support rates corresponding to the ratio of total hypotheses minus the rejected hypotheses to the total number of tested hypotheses, and their standard deviation values (SD) are indicated for each model.

modified to exclude canopy, which would reduce to model 3. Similarly, model 2 predicts that the pattern of gene flow is only a function of distance. However, we found a significant correlation between the river and the pattern of gene flow while controlling the effect of distance (Hypothesis MG.D, S). This suggests that the river should be added to this model, producing again model 3 .
Model $3(\mathrm{D}+\mathrm{M})$ thus appears to explain best most significant and NS correlations while keeping the number of factors to a limited level (two factors instead of three for model 1). Additionally to the tests performed on the whole data set and to control for the Manankolana River effect, we also performed causal modelling analyses on each side of the river. For both sides, the Isola- 
Table 3 Organizational models for the two sides of the river

\begin{tabular}{|c|c|c|c|c|c|c|c|c|c|}
\hline $\begin{array}{l}\text { Resistance hypothesis } \\
\text { (Partial Mantel test) }\end{array}$ & $R$ & $P$ value & $\mathrm{D}$ & $\mathrm{C}+\mathrm{D}$ & $\mathrm{D}+\mathrm{R}$ & $\mathrm{C} 4$ & $\mathrm{R}+\mathrm{D}+\mathrm{C}$ & $\mathrm{R}$ & $\mathrm{C} 4+\mathrm{R}$ \\
\hline \multicolumn{10}{|l|}{ Eastern side } \\
\hline DG.R & 0.212 & $<0.001$ & $S$ & $S$ & NS & & $S$ & NS & NS \\
\hline C4G.R & 0.115 & 0.002 & & $S$ & NS & $\mathrm{S}$ & $\mathrm{S}$ & NS & NS \\
\hline RG.D & -0.035 & 0.896 & NS & NS & $S$ & & S & $S$ & S \\
\hline RG.C4 & -0.055 & 0.977 & & NS & $\mathrm{S}$ & NS & S & $\mathrm{S}$ & S \\
\hline C4G.D & -0.012 & 0.641 & NS & $S$ & NS & $S$ & S & & $\mathrm{S}$ \\
\hline \multirow[t]{3}{*}{ DG.C4 } & 0.185 & $<0.001$ & $S$ & $\mathrm{~S}$ & $\mathrm{~S}$ & NS & $S$ & & NS \\
\hline & Support rate & Mean & 0.99 & 0.837 & 0.33 & 0.51 & 0.5 & 0.01 & 0.01 \\
\hline & & $\mathrm{SD}$ & 0.05 & 0.047 & 0.05 & 0.07 & 0.05 & 0.04 & 0.05 \\
\hline $\begin{array}{l}\text { Resistance hypothesis } \\
\text { (Partial Mantel test) }\end{array}$ & $R$ & $P$ value & $C 4+D$ & $\mathrm{D}$ & $\mathrm{R}+\mathrm{D}+\mathrm{C} 4$ & $\mathrm{C} 4$ & $\mathrm{C} 4+\mathrm{R}$ & $D+R$ & $\mathrm{R}$ \\
\hline \multicolumn{10}{|l|}{ Western side } \\
\hline DG.R & 0.2529 & $<0.001$ & $\mathrm{~S}$ & $\mathrm{~s}$ & $\mathrm{~S}$ & & NS & NS & NS \\
\hline C4G.R & 0.238 & $<0.001$ & $\mathrm{~S}$ & & $\mathrm{~S}$ & S & NS & NS & NS \\
\hline RG.D & -0.03208 & 0.958 & NS & NS & $\mathrm{S}$ & & S & S & S \\
\hline RG.C4 & 0.02793 & 0.059 & NS & & $\mathrm{S}$ & NS & $S$ & S & S \\
\hline C4G.D & 0.138 & $<0.001$ & $\mathrm{~S}$ & NS & $\mathrm{S}$ & S & S & NS & \\
\hline \multirow[t]{3}{*}{ DG.C4 } & 0.1625 & $<0.001$ & $\mathrm{~S}$ & $\mathrm{~S}$ & $\mathrm{~S}$ & NS & S & $S$ & \\
\hline & Support rate & Mean & 0.92 & 0.75 & 0.75 & 0.63 & 0.41 & 0.25 & 0.12 \\
\hline & & $\mathrm{SD}$ & 0.08 & 0 & 0.08 & 0.13 & 0.08 & 0.08 & 0.13 \\
\hline
\end{tabular}

See Table 2 for legend.

tion-By-Distance model was the only fully supported model, hence confirming our previous results (data not shown). We also modelled the Isolation-by-canopy hypothesis as a new categorical model matrix [C4] with the values of 1 and 0 corresponding to pairs of individuals located within the same patch, or in different patches, respectively. Interestingly, we observed, in this case, that the model D + C (Distance and Canopy) was the best supported model for individuals located on the west side of the river whereas the model $\mathrm{D}$ was still the best model for the east side (Table 3). When we excluded individuals from Antsaharaingy, the model D was again the best supported for the west side (data not shown).

\section{Scale of isolation-by-distance}

Significant and positive autocorrelation values were obtained in the first four distance classes (Fig. 4), corresponding to distances less than $1500 \mathrm{~m}$. The highest value was observed in the first distance class corresponding to comparisons between individuals from the same social groups $(r=0.244, P$ value $<0.001)$. The autocorrelogram then flatten out and the autocorrelation coefficient stabilised around 0.08 in the following three distance classes before reaching values around zero between 1500 and $2000 \mathrm{~m}$. Then, the values remained slightly negative but were not significant up to $5000 \mathrm{~m}$, as expected when there is isolation by distance.

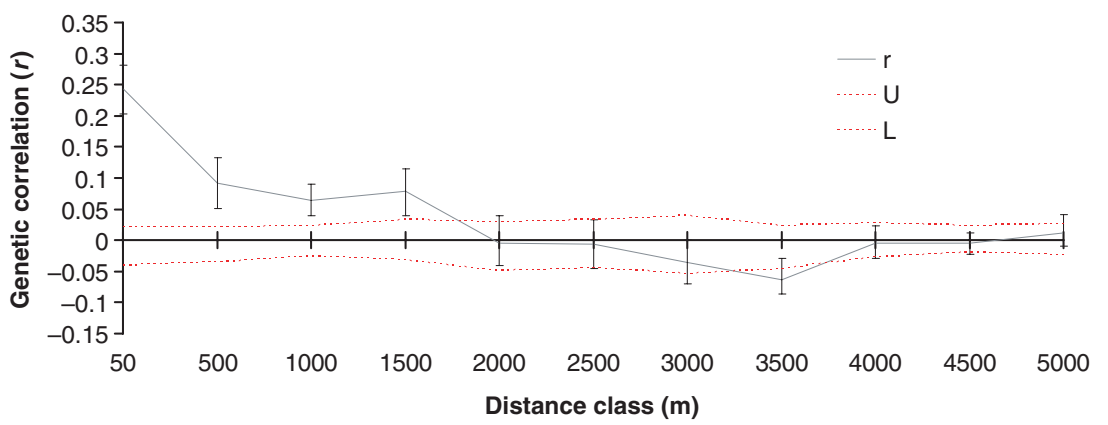

Fig. 4 Spatial autocorrelation analysis. Correlogram plots of the spatial genetic autocorrelation coefficient $r$ as a function of distance for individuals within forest fragments. Upper (U) and lower (L) bounds for the 95\% confidence interval for the null hypothesis of no spatial structure $(r=0)$ and the upper Ur and lower Lr 95\% error bars about $r$ as determined by bootstrap resampling are shown. 


\section{Discussion}

\section{A high-genetic diversity within a small distribution range?}

The level of genetic diversity observed for the goldencrowned sifaka (MNA $=7.7$ and $H_{\mathrm{e}}=0.74$ across loci and for all samples) appeared higher than we expected for a species living in one of the smallest range and most fragmented habitats of any lemur. Comparing this estimate with those obtained from closely related species remains problematic as population genetic studies on other sifakas are still limited and often carried out using a restricted number of individuals or locations due to the difficulty in capturing sifakas. Only one study conducted on a large number of Propithecus verreauxi (>200 individuals) from the Beza Mahafaly Special Reserve protected area (Lawler et al. 2001; Lawler et al. 2003) could be used as a comparison. Although this species is known to have a wider range and a less disturbed habitat than Propithecus tattersalli, the authors found similar values of genetic diversity (MNA $=9.29$ and $\left.H_{\mathrm{e}}=0.74\right)$. Furthermore, the level of genetic diversity found in this study are higher than those observed for three Microcebus and one Lepilemur species (L. edwardsi), even though these species are expected to have larger effective population sizes (Olivieri et al. 2008; Craul et al. 2009). For $L$ edwardsi, the low diversity observed (MNA $\leq 4$ across 14 loci and $H_{\mathrm{e}}=0.55$ ) seems to be due to the fact that the species is currently heavily hunted and undergoing a significant reduction in population size (Craul et al. 2009). The comparisons with the Microcebus should be taken cautiously because of ascertainment bias introduced by the choice of the microsatellite loci. Loci used in Olivieri et al. 2008 were originally developed for Microcebus murinus and were thus expected to produce an underestimation of genetic diversity (Chikhi 2008). Altogether we would like to emphasize that the comparison of levels of genetic diversity across species remains a tricky issue, as it heavily depends on how loci were isolated and how the sampling was performed.

\section{The role of the Manankolana River as a major gene flow barrier}

One of the main results of our study was that we clearly identified the Manankolana River as a major geographical feature shaping genetic differentiation in $P$. tattersalli and as possibly the main barrier to dispersal in the Daraina region. This result was surprising at first given that the river is dry most of the year, and particularly during our fieldwork, and hence should not be more difficult to cross than many other open areas. One possible interpretation could be that this pat- tern is the result of significant human presence as many villages and rice fields are located near the river. Another plausible explanation to this pattern is related to the sifakas dispersal behaviour. Indeed, behavioural studies by Meyers (1993) have shown that most of the dispersal events between groups appear to take place during the mating season, which occurs in the middle of the rainy season when the river is full and therefore represents a significant barrier to dispersal. This is supported by the fact that rivers are increasingly recognised as barriers to gene flow in many primate species, both outside (Eriksson et al. 2004; Goossens et al. 2005) and in Madagascar (Mittermeier et al. 2008) and that this role has also been confirmed across other taxa in Madagascar (Wilmé et al. 2006; Yoder \& Nowak, 2006). This is particularly clear in the Microcebus and Lepilemur genera where many new species have been shown to have very small ranges whose limits are rivers (Radespiel et al. 2008a, b; Louis et al. 2006; Mittermeier et al. 2008). Also, the geographical range of $P$. tattersalli is nearly entirely delimited by two rivers, the Manambato and the Loky. The only exception is a small population north-west of the Loky (Fig. 1), in the most upstream region of this river.

\section{The role of isolation by distance}

One of the main results provided by the causal modelling approach is that the geographical distance (together with the Manankolana River) appeared to be the main population-structuring factor in $P$. tattersalli. This suggests that $P$. tattersalli effective migration events are mostly between neighbouring groups, and was confirmed by the spatial autocorrelation analysis. This analysis showed that the highest autocorrelation values were found at the smallest spatial scale, within groups (Fig. 4), suggesting that most individuals within social groups are closely related. This result is probably due to the fact that sifaka social groups are likely including lineages of philopatric related females and young males born in the group who have not dispersed yet (Meyers 1993). We also observed a significant spatial autocorrelation among pairs of individuals in the first four distance classes (i.e. at distances $<1500 \mathrm{~m}$ ). These four classes included $87 \%$ of the distances between individuals and the nearest groups hence suggesting that (i) our sampling scheme was appropriate to assess finescale structure and (ii) most dispersal events within forest patches occur among neighbouring groups. This result is again in agreement with the behavioural studies on P. tattersalli (Meyers 1993) and also on P. verreauxi (Richard et al. 1993). These authors observed, in a 5-year census period, that all Verreaux's sifakas males migrated to groups no more than two home ranges 
away from their natal group. As suggested by Richard (1985) and Richard et al. (1993), these patterns of adjacent transfers cause some neighbouring groups to have related males, thus resulting in a 'neighbourhood-like' social organization.

\section{Impact of forest habitat fragmentation on $\mathrm{P}$. tattersalli dispersal}

The clustering and causal modelling approaches brought us complementary and interesting results about how the golden-crowned sifakas respond to current habitat fragmentation at both landscape and patch scales. At the landscape scale (i.e. entire species range), the results of the causal modelling approach suggest that canopy connectivity is not a major population structuring factor. This is in agreement with the clustering analysis since two of the three uncovered genetic units included several forest patches, suggesting that effective dispersal is actually occurring between at least some patches. A relatively large network of riparian gallery forests has been maintained and we suggest that they could have contributed to preserving dispersal between most of the forest patches. However, when we explored the results at the smaller, regional scale, the situation appeared to be more complex. Indeed, the STRUCTURE results showed that habitat fragmentation and hence connectivity had a strong impact on dispersal, since we found a significant genetic discontinuity in the very north of the Daraina area, identifying Antsaharaingy as a cluster $(\mathrm{KC})$. This highlights one limitation of the causal modelling approach that can only identify general processes working at the entire sampling scale (i.e. the landscape scale). Here, habitat fragmentation appears to be important in only one region, but this effect is averaged out with other regions where fragments are still connected, leading to a NS effect when the whole region is considered. Interestingly, we observed that the model implementing Isolation-by-canopy hypothesis obtained the highest support when we restricted the causal modelling approach to individuals located on the west side of the Manankolana River and used a categorical model (C4) to represent the Isolationby-canopy hypothesis.

Altogether (if we exclude the isolated Antsaharaingy forest), our results are in agreement with a weak influence of forest habitat structural connectivity on sifaka dispersal, not because habitat fragmentation is not a potential threat for this species but because in most regions, forest fragments are still close enough from each other or still connected by corridors. Two radically different historic scenarios of forest fragmentation may explain our results. First, if the forest fragmentation process in the Daraina area was recent then we would expect to find a limited level of genetic differentiation between forest patches, even if migration had stopped at the present time. Indeed, the genetic structure can have a substantial time lag in its response to changes in gene flow (Wright 1978; Waples 1998). This possible time lag is difficult to assess since it may be influenced by many factors such as the nature of the genetic markers employed, the population size and the level of substructure before fragmentation, and mating patterns (Balkenhol et al. 2009). Although aerial and satellite images suggest that forest patch boundaries in the Daraina region have been relatively stable in the last 50 years (Jimenez \& Vargas, 2000), we currently have no data before this date. We thus cannot determine whether the habitat was continuous before the 1950s. The current patterns of genetic differentiation could thus potentially be the result of very recent fragmentation, say during the first half of the 20th century. Under the second scenario, the forest fragmentation could be significantly more ancient, perhaps a few centuries or millennia old. In this scenario, the golden-crowned sifaka may have 'adapted' to the fragmented landscape, and genetic differentiation observed today would correspond to the actual migration events between presentday populations and fragments. This second scenario is supported by the fact that we observed sifakas moving on the ground on several occasions (EQ pers. obs.). Jimenez \& Vargas (2000) also observed P. tattersalli individuals crossing more than $200 \mathrm{~m}$ of grasslands to reach the closest forest. They also showed that goldencrowned sifakas were able to survive in riparian forests and forest fragments smaller than $10 \mathrm{ha}$, which were sometimes located more than $2 \mathrm{~km}$ away from the closest large forest. Additionally, they noted that straight line distances better explained the presence of $P$. tattersalli in forest fragments than the presence or absence of corridors among forest patches.

\section{On the use of causal and least-cost modelling}

Here, we presented a practical case in which causal modelling was used to identify key features influencing patterns of genetic differentiation. As expected we found that the use of simple Mantel tests to identify structuring factors (see Epps 2007; Coulon 2004) could produce spurious correlations (Cushman et al. 2006). The reason for this is that different factors may be correlated among themselves, and a significant test may not be due to a particular factor but to another one to which it is correlated. The causal modelling approach, by explicitly stating different partial tests and comparing the support for competing hypotheses, appeared able to identify at least some of these spurious correlations. Used together with STRUCTURE, it allowed us to 
identify important factors and importantly some limitations. First, the analysis is necessarily dependent on the factors identified a priori as potentially important. This means that some ecological and behavioural knowledge of the species may be required on habitat and corridor preferences to define least-cost paths. Second, potentially important factors in one sub-region may not be detected as such when the analysis is performed across the whole region, as we saw above. The joint use of clustering methods may thus be necessary, particularly as they do not require much prior information.

Another point to keep in mind in our case is that the configuration of the forest habitat in the Daraina region may have played a role in the results. Indeed, the surface area of several forest patches was relatively large compared to the distances between patches and to the total area of the distribution range. The distance between some individuals belonging to the same patch could thus be higher than the distance between individuals belonging to different patches. This could explain why it was difficult to demonstrate an effect of connectivity. Indeed, we found a high correlation between the geographical distance and the least-cost distances that were maximizing the amount of forest areas in a particular path. This was observed for all the levels of selectivity used for the canopy factor. Thus, we suspect that least-cost modelling analyses might work better when the geographical scale of the study is significantly greater than the dispersal ability of the species of interest (Vignieri 2005; Epps et al. 2007; Spear \& Storfer 2008; Perez-Barberia et al. 2008; Clark et al. 2008).

\section{Conclusions and implications for conservation}

Altogether, our results suggest that the golden-crowned sifakas maintain dispersal among most of the forest fragments. However, a regular monitoring of this species is needed since important human disturbances are expected in the near future in the Daraina area. There is an impending installation of a major gold-mining company and the anticipated tarring of the national road. Furthermore, the recent political events in Madagascar have led to an increase in Propithecus tattersalli killing by poachers. The SFUM currently includes the following forest patches: Bekaraoka, Bobankora, BAA, Antsaharaingy and Ampondrabe. Unfortunately, these patches do not include Ampoetany, Tsarahitsaka and Bemokoty which harbour the highest population densities (Quéméré et al. 2010) among the populations belonging to the genetic clusters from the west side of the river. Clearly, the incorporation of these fragments to the SFUM seems to be a necessity from both the genetic and demographic point of view.

\section{Acknowledgements}

Financial support for this study was provided by CNRS and the French ministry of Research core funding to UMR5174 CNRS Université Paul Sabatier. EQ was funded by a MNRT (Ministère de l'Education Nationale, de la Recherche et de la Technologie) PhD grant. The field work was possible thanks to the support of the following associations and NGOs: IDEA WILD, CEPA (Conservation des Espèces et Populations Animales, notably J.-M. Lernould) and FANAMBY (in particular S. Rajaobelina, S. Wohlhauser and McG. Ranaivo Arivelo). We warmly thank the Daraina local communities for welcoming us, Julie Champeau, Aubin Besolo, Emmanuel Rasolondraibe, all guides and research assistants for their precious help on the field. We thank CAFF/CORE, the 'Direction générale des Eaux et Forêt' for giving us permission to conduct the fieldwork in Madagascar and for the authorizations to export the samples. We also thank A. Coutinho for his continuous support and for facilitating visits between the IGC and EDB. We also thank Kyle Dexter, Simon Blanchet and four anonymous referees for useful and constructive comments which helped us improve the manuscript significantly. The lab work was funded by European Commission (research contract QLRI-CT-2002-01325 INPRIMAT), the Center of Conservation and Research (CCR), Omaha's Henry Doorly Zoo (Nebraska, USA), where the microsatellites were isolated and the Institut Francais de la Biodiversité, Programme Biodiversité de l'Océan Indien. LC was also partly funded by the FCT grant PTDC/BIA$\mathrm{BDE} / 71299 / 2006$

\section{References}

Aars J, Dallas JF, Piertney SB et al. (2006) Widespread gene flow and high genetic variability in populations of water voles Arvicola terrestris in patchy habitats. Molecular Ecology, 15, 1455-1466.

Adriaensen F, Chardon JP, De Blust G et al. (2003) The application of 'least-cost' modelling as a functional landscape model. Landscape and Urban Planning, 64, 233-247.

Allnutt TF, Ferrier F, Manion G et al. (2008) A method for quantifying biodiversity loss and its application to a 50-year record of deforestation across Madagascar. Conservation Letters, 1, 173-181.

Anderson EC, Dunham KK (2008) The influence of family groups on inferences made with the program Structure. Molecular Ecology Resources, 8, 1219-1229.

Andrén H (1994) Effects of habitat fragmentation on birds and mammals in landscapes with different proportions of suitable habitat: a review. Oikos, 71, 355-366.

Balkenhol N, Gugerli F, Cushman S et al. (2009) Identifying future research needs in landscape genetics: where to from here? Landscape Ecology, 24, 455-463.

Banks SC, Lindenmayer DB, Ward SJ, Taylor AC (2005) The effects of habitat fragmentation via forestry plantation establishment on spatial genotypic structure in the small marsupial carnivore, Antechinus agilis. Molecular Ecology, 14, 1667-1680.

Belkhir K, Borsa P, Chikhi L, Raufaste N, Bonhomme F (19962004) GENETIX 4.05, logiciel sous Windows TM pour la génétique des populations. Laboratoire Génome, Populations, 
Interactions, CNRS UMR 5171, Université de Montpellier II, Montpellier (France).

Bergl RA, Vigilant L (2007) Genetic analysis reveals population structure and recent migration within the highly fragmented range of the Cross River gorilla (Gorilla gorilla diehli). Molecular Ecology, 16, 501-516.

Broquet T, Johnson CA, Petit E et al. (2006) Dispersal and genetic structure in the American marten, Martes americana. Molecular Ecology, 15, 1689-1697.

Chikhi L, Bruford MW (2005) Mammalian population genetics and genomics. In: Mammalian Genomic (eds Ruvinsky A, Marshall Graves J), pp. 539-584. CABI Publishers, UK.

Chikhi L (2008) Genetic markers: how accurate can genetic data be? Heredity, 101, 471-472.

Clark RW, Brown WS, Stechert R, Zamudio KR (2008) Integrating individual behaviour and landscape genetics: the population structure of timber rattlesnake hibernacula. Molecular Ecology, 17, 719-730.

Coulon A, Cosson JF, Angibault JM et al. (2004) Landscape connectivity influences gene flow in a roe deer population inhabiting a fragmented landscape: an individual-based approach. Molecular Ecology, 13, 2841-2850.

Coulon A, Guillot G, Cosson JF et al. (2006) Genetic structure is influenced by landscape features: empirical evidence from a roe deer population. Molecular Ecology, 15, 1669-1679.

Craul M, Chikhi L, Sousa V, Olivieri G, Rabesandratana A, Zimmermann E, Radespiel U (2009) Influence of forest fragmentation on an endangered large-bodied lemur in northwestern Madagascar. Biological Conservation, 142, 28622871.

Crnokrak P, Roff DA (1999) Inbreeding depression in the wild. Heredity, 83, 260-270.

Cushman SA (2006) Effects of habitat loss and fragmentation on amphibians: a review and prospectus. Biological Conservation, 128, 231-240.

Cushman SA, McKelvey KS, Hayden J, Schwartz MK (2006) Gene flow in complex landscapes: testing multiple hypotheses with causal modeling. American Naturalist, 168, 486-499.

Cushman SA, McKelvey KS, Schwartz MK (2009) Use of empirically derived source-destination models to map regional conservation corridors. Conservation Biology, 23, 368376.

Dunham AE, Erhart EM, Overdorff DJ, Wright PC (2008) Evaluating effects of deforestation, hunting, and El Nino events on a threatened lemur. Biological Conservation, 141, 287-297.

Epps CW, Palsboll PJ, Wehausen JD et al. (2005) Highways block gene flow and cause a rapid decline in genetic diversity of desert bighorn sheep. Ecology Letters, 8, 1029-1038.

Epps CW, Wehausen JD, Bleich VC, Torres SG, Brashares JS (2007) Optimizing dispersal and corridor models using landscape genetics. Journal of Applied Ecology, 44, 714-724.

Eriksson J, Hohmann G, Boesch C, Vigilant L (2004) Rivers influence the population genetic structure of bonobos (Pan paniscus). Molecular Ecology, 13, 3425-3435.

Evanno G, Regnaut S, Goudet J (2005) Detecting the number of clusters of individuals using the software STRUCTURE: a simulation study. Molecular Ecology, 14, 2611-2620.

Evett IW, Weir BS (1998) Interpreting DNA Evidence. Sinauer, Sunderland, MA.
Fahrig L (2003) Effects of habitat fragmentation on biodiversity. Annual Review of Ecology, Evolution, and Systematics, 34, 487-487.

Fahrig L, Merriam G (1994) Conservation of fragmented populations. Conservation Biology, 8, 50-59.

Falush D, Stephens M, Pritchard JK (2003) Inference of population structure using multilocus genotype data: linked loci and correlated allele frequencies. Genetics, 164, 15671587.

Foley JA, DeFries R, Asner GP et al. (2005) Global consequences of land use. Science, 309, 570-574.

Frankham R (2005) Conservation biology-ecosystem recovery enhanced by genotypic diversity. Heredity, 95, 183-183.

Frankham R, Ballou J, Briscoe D (2002) An Introduction to Conservation Genetics. Cambridge University Press, Cambridge, UK.

Frantz AC, Pope LC, Carpenter PJ et al. (2003) Reliable microsatellite genotyping of the Eurasian badger (Meles meles) using faecal DNA. Molecular Ecology, 12, 1649-1661.

Ganzhorn J, Goodman S, Dehgan A (2003) Effects of forest fragmentation on small mammals and lemurs. In: The Natural History of Madagasca (eds Goodman SM, Benstead JP), pp. 1228-1234. University of Chicago Press, Chicago.

Ganzhorn JU, Fietz J, Rakotovao E, Schwab D, Zinner D (1999) Lemurs and the regeneration of dry deciduous forest in Madagascar. Conservation Biology, 13, 794-804.

Goossens B, Chikhi L, Jalil MF et al. (2005) Patterns of genetic diversity and migration in increasingly fragmented and declining orang-utan (Pongo pygmaeus) populations from Sabah, Malaysia. Molecular Ecology, 14, 441-456.

Goudet J (2001) FSTAT, A Program to Estimate and Test Gene Diversities and Fixation Indices (version 2.9.3). Université de Lausanne, Lausanne, Suisse.

Green GM, Sussman RW (1990) Deforestation history of the Eastern rain forests of Madagascar from satellite images. Science, 248, 212-215.

Guillot G, Leblois R, Coulon A, Frantz AC (2009) Statistical methods in spatial genetics. Molecular Ecology, 18, 47344756.

Hardy OJ, Vekemans X (2002) SPAGEDi: a versatile computer program to analyse spatial genetic structure at the individual or population levels. Molecular Ecology Notes, 2, 618-620.

Harper GJ, Steininger MK, Tucker CJ, Juhn D, Hawkins F (2007) Fifty years of deforestation and forest fragmentation in Madagascar. Environmental Conservation, 34, 325-333.

Holderegger R, Wagner HH (2008) Landscape Genetics. BioScience, 58, 199-207.

Irwin MT (2007) Living in forest fragments reduces group cohesion in diademed sifakas (Propithecus diadema) in eastern Madagascar by reducing food patch size. American Journal of Primatology, 69, 434-447.

Jimenez I, Vargas A (2000) A Report on the Conservation Status of the Golden-crowned Sifaka (Propithecus tattersalli) (Unpublished Report, October). Association Fanamby, Antananarive, Madagascar.

Johansson M, Primmer CR, Merila J (2007) Does habitat fragmentation reduce fitness and adaptability? A case study of the common frog (Rana temporaria). Molecular Ecology, 16, 2693-2700.

Kalinowski ST, Taper ML, Marshall TC (2007) Revising how the computer program CERVUS accommodates genotyping 
error increases success in paternity assignment. Molecular Ecology, 16, 1099-1106.

Keller LF, Waller DM (2002) Inbreeding effects in wild populations. Trends in Ecology \& Evolution, 17, 230-241.

Kindlmann P, Burel F (2008) Connectivity measures: a review. Landscape Ecology, 23, 879-890.

Kohn MH, York EC, Kamradt DA et al. (1999) Estimating population size by genotyping faeces. Proceedings of Biological Sciences, 266, 657-663.

Laurance W, Peres C (2006) Emerging Threats to Tropical Forests. University of Chicago Press, Chicago.

Lawler RR, Richard AF, Riley MA (2001) Characterization and screening of microsatellite loci in a wild lemur population (Propithecus verreauxi verreauxi). American Journal of Primatology, 55, 253-259.

Lawler RR, Richard AF, Riley MA (2003) Genetic population structure of the white sifaka (Propithecus verreauxi verreauxi) at Beza Mahafaly Special Reserve, southwest Madagascar (1992-2001). Molecular Ecology, 12, 2307-2317.

Legendre P (1993) Spatial autocorrelation: trouble or new paradigm? Ecology, 74, 1659-1673.

Legendre P, Legendre L (1998) Numerical Ecology. Elsevier Science BV, Amsterdam, The Netherlands.

Lehman SM, Rajaonson A, Day S (2006) Edge effects and their influence on lemur density and distribution in Southeast Madagascar. American Journal of Physical Anthropology, 129, 232-241.

Lindenmayer D, Hobbs RJ, Montague-Drake R et al. (2008) A checklist for ecological management of landscapes for conservation. Ecology Letters, 11, 78-91.

Louis Jr. EE, Engberg SE, Lei R et al. (2006) Molecular and morphological analyses of the sportive lemurs (Family Megaladapidae: Genus Lepilemur) reveals 11 previously unrecognized species. Special Publications of the Museum of Texas Tech University, ???, 1-47.

Manel S, Schwartz MK, Luikart G, Taberlet P (2003) Landscape genetics: combining landscape ecology and population genetics. Trends in Ecology \& Evolution, 18, 189-197.

Mantel N (1967) The detection of disease clustering and a generalized regression approach. Cancer Research, 27, 209220.

Manly BFJ (1997). Randomization, Bootstrap and Monte Carlo Methods in Biology. Chapman \& Hall, London.

Meyers DM (1993) The Effects of Resource Seasonality on the Behavior and Reproduction of the Golden-crowned Sifaka (Propithecus tattersalli, Simons, 1988) in three Malagasy Forests. Duke University, University Microfilms, Ann Arbor, MI, USA.

Miquel C, Bellemain E, Poillot C, et al. (2006) Quality indexes to assess the reliability of genotypes in studies using noninvasive sampling and multiple-tube approach. Molecular Ecology Notes, 6, 985-988.

Mittermeier RA, Konstant WR, Hawkins F et al. (2006) Conservation International Tropical Field Guide Series: Lemurs of Madagascar, 2 edn. Washington D. C. Conservation International.

Mittermeier R, Ganzhorn J, Konstant W et al. (2008) Lemur Diversity in Madagascar. International Journal of Primatology, 29, 1607-1656.

Myers N, Mittermeier RA, Mittermeier CG, da Fonseca GA, Kent J (2000) Biodiversity hotspots for conservation priorities. Nature, 403, 853-858.
Nei M (1978) Estimation of average heterozygosity and genetic distance from a small number of individuals. Genetics, 89, 583-590.

Olivieri GL, Sousa V, Chikhi L, Radespiel U (2008) From genetic diversity and structure to conservation: genetic signature of recent population declines in three mouse lemur species (Microcebus spp.). Biological Conservation, 141, 1257-1271.

Peakall R, Ruibal M, Lindenmayer DB (2003) Spatial autocorrelation analysis offers new insights into gene flow in the Australian bush rat, Rattus fuscipes. Evolution, 57, 11821195.

Peakall R, Smouse PE (2006) genalex 6: genetic analysis in Excel. Population genetic software for teaching and research. Molecular Ecology Notes, 6, 288-295.

Perez-Barberia FJ, Jiggins CD, Gordon IJ, Pemberton JM (2008) Landscape features affect gene flow of Scottish Highland red deer (Cervus elaphus). Molecular Ecology, 17, 981-996.

Pritchard JK, Stephens M, Donnelly P (2000) Inference of population structure using multilocus genotype data. Genetics, 155, 945-959.

Pritchard JK, Wen X, Falush D (2007) Documentation for Structure Software. Version 2.2. Department of Human Genetics, University of Chicago, Chicago, IL.

Quéméré E, Louis E, Ribéron A, Chikhi L, Crouau-Roy B (2009) Non-invasive conservation genetics of the critically endangered golden-crowned sifaka (Propithecus tattersalli): high diversity and significant genetic differentiation over a small range. Conservation Genetics. DOI 10.1007/s10592-0099837-9.

Quéméré E, Champeau J, Besolo A et al. (2010) Spatial variation in density and total size estimates in fragmented primate populations: the golden-crowned sifaka (Propithecus tattersalli). American Journal of Primatology, 72, 72-80.

Radespiel U, Olivieri G, Rasolofoson DW et al. (2008a) Exceptional diversity of mouse lemurs (Microcebus spp.) in the Makira region with the description of one new species. American Journal of Primatology, 70, 1033-1046.

Radespiel U, Rakotondravony R, Chikhi L (2008b) Natural and anthropogenic determinants of genetic structure in the largest remaining population of the endangered goldenbrown mouse lemur, Microcebus ravelobensis. American Journal of Primatology, 70, 860-870.

Ray N (2005) PATHMATRIX: a geographical information system tool to compute effective distances among samples. Molecular Ecology Notes, 5, 177-180.

Richard AF (1985) Social boundaries in a Malagasy Prosimian, the Sifaka (Propithecus verreauxi). International Journal of Primatology, 6, 553-568.

Richard AF, Rakotomanga P, Schwartz M (1993) Dispersal by Propithecus verreauxi at Beza Mahafaly, Madagascar. American Journal of Primatology, 30, 1-20.

Rousset F (2000) Genetic differentiation between individuals. Journal of Evolutionary Biology, 13, 58-62.

Saccheri I, Kuussaari M, Kankare M et al. (1998) Inbreeding and extinction in a butterfly metapopulation. Nature, 392, 491-494.

Sala OE, Chapin FS, Armesto JJ et al. (2000) Biodiversity - global biodiversity scenarios for the year 2100 . Science, 287, 1770-1774.

Scott DM, Brown D, Mahood S et al. (2006) The impacts of forest clearance on lizard, small mammal and bird 
communities in the arid spiny forest, southern Madagascar. Biological Conservation, 127, 72-87.

Smith PS (1997) Deforestation, fragmentation, and reserve design in western Madagascar. In: Tropical Forest Remnants: Ecology, Management, and Conservation of Fragmented Communitie (eds Laurance WF, Bierregaard RO), pp. 415-441. The University of Chicago Press, Chicago and London.

Smouse PE, Long JC, Sokal RR (1986) Multiple regression and correlation extensions of the Mantel test of matrix correspondence. Systematic Zoology, 35, 627-632.

Spear SF, Storfer A (2008) Landscape genetic structure of coastal tailed frogs (Ascaphus truei) in protected vs. managed forests. Molecular Ecology, 17, 4642-4656.

Storfer A, Murphy MA, Evans JS et al. (2007) Putting the "landscape" in landscape genetics. Heredity, 98, 128-142.

Taberlet P, Griffin S, Goossens B et al. (1996) Reliable genotyping of samples with very low DNA quantities using PCR. Nucleic Acids Research, 24, 3189-3194.

Taberlet P, Camarra JJ, Griffin S et al. (1997) Noninvasive genetic tracking of the endangered Pyrenean brown bear population. Molecular Ecology, 6, 869-876.

Taylor P, Fahrig L, A K (2006) Landscape connectivity: back to the basics in connectivity conservation. In: Conservation Biolog (eds Crooks K, Sanjayan M), pp. 29-43. Cambridge University Press, Cambridge.

Vallet D, Petit EJ, Gatti S, Levrero F, Menard N (2008) A new 2CTAB/PCI method improves DNA amplification success from faeces of Mediterranean (Barbary macaques) and tropical (lowland gorillas) primates. Conservation Genetics, 9, 677-680.

Vargas A, Jimenez I, Palomares F, Palacios MJ (2002) Distribution, status, and conservation needs of the goldencrowned sifaka (Propithecus tattersalli). Biological Conservation, 108, 325-334.

Vignieri SN (2005) Streams over mountains: influence of riparian connectivity on gene flow in the Pacific jumping mouse (Zapus trinotatus). Molecular Ecology, 14, 1925-1937.

Walker FM, Sunnucks P, Taylor AC (2008) Evidence for habitat fragmentation altering within-population processes in wombats. Molecular Ecology, 17, 1674-1684.

Waples RS (1998) Separating the wheat from the chaff: patterns of genetic differentiation in high gene flow species. Journal of Heredity, 89, 438-450.

Weir BS, Cockerham CC (1984) Estimating F-statistics for the analysis of population-structure. Evolution, 38, 13581370 .
Wilme L, Goodman SM, Ganzhorn JU (2006) Biogeographic evolution of Madagascar's microendemic biota. Science, 312, 1063-1065.

Wright S (1978) Evolution and the Genetics of Populations, Vol. 4, Variability Within and Among Natural Populations. University of Chicago Press, Chicago, IL.

Yoder AD, Nowak MD (2006) Has vicariance or dispersal been the predominant biogeographic force in Madagascar? Only time will tell. Annual Review of Ecology Evolution and Systematics, 37, 405-431.

ZICOMA (1999) Les Zones d'Importance pour la Conservation des Oiseaux à Madagascar. Project ZICOMA, Antananarivo, Madagascar.

This study forms part of Erwan Quéméré's PhD on conservation genetics of golden-crowned sifaka. Lounès Chikhi is a population geneticist interested in inferring ancient population demography using molecular markers, with an emphasis on humans and conservation biology. Edward E. Louis Jr. is a conservation biologist at Omaha Zoo, Nebraska, and specialist of Malagascascan fauna. Clément Rabarivola is a primatologist working on the conservation of primates in Madagascar. Brigitte Crouau-Roy is an evolutionary biologist and population geneticist particularly interested in the molecular evolution of primate genome. She is at the head of the laboratory 'Evolution et Diversité Biologique', Université Paul Sabatier, Toulouse, France.

\section{Supporting Information}

Additional supporting information may be found in the online version of this article.

Fig. S1 Models of habitat structural connectivity.

Fig. S2 Description of the 15 tested organizational models.

Table S1 Pairwise $F_{\mathrm{ST}}$ values.

Please note: Wiley-Blackwell are not responsible for the content or functionality of any supporting information supplied by the authors. Any queries (other than missing material) should be directed to the corresponding author for the article. 